\title{
The power of peer-review: A tool to improve student skills and unit satisfaction
}

\author{
Ruth Wallace', Shelley Beatty ${ }^{1}$, Jo Lines², Catherine Moore², Leesa Costello \\ ${ }^{1}$ Public Health, Edith Cowan University, Australia, ${ }^{2}$ Centre for Learning and Teaching, Edith \\ Cowan University, Australia.
}

\begin{abstract}
Providing higher education students with opportunities to participate in peerreview feedback activities may facilitate interaction between students and enhance academic skills. Such activities are reported to help students transition from passive to active learners whilst increasing social connectedness and developing employability skills. This research aimed to evaluate student perceptions of a peer-review of assessment process offered in an undergraduate Health Science unit at Edith Cowan University in Western Australia, and their subsequent unit satisfaction.

Before students began the peer-review process, a sample assignment was used to coach them on how to provide constructive feedback. They subsequently prepared a draft of their assignment for peer-review, and then reviewed the work of another student. Pre-and post-surveys were administered to assess students' perceptions about the usefulness of the peer-review activity.

Thirty-two students completed the pre-survey wherein $94 \%(n=30)$ reported the peer-review coaching helped them prepare their own assignment and $85 \%$ $(n=27)$ reported learning how to provide constructive written feedback. Twenty-one students completed the post-survey, $76 \%(n=16)$, reporting they modified their own assignment as an outcome of their peer-review participation. Many respondents also reported improvements in their critical thinking (76\%; $n=16)$ and written communication skills $(62 \% ; n=13)$. Overall unit satisfaction increased exponentially.
\end{abstract}

Keywords: Peer-review feedback; higher education; assessment. 


\section{Introduction}

Effective feedback is important for student success (Wanner \& Palmer, 2018). Providing effective feedback on student assignments is a significant issue in Australian higher education (Moore \& Teather, 2013); ideally it should be considered a two-way conversation rather than a one-way communication process (Nicol, Thomson, \& Breslin, 2014). Feedback has been described as a 'loop', whereby the process can be considered complete once the feedback results in improved performance, demonstrating that learning has occurred (Moore \& Teather, 2013).

Although there is evidence that university students benefit from student-centred learning opportunities, these are not always provided in Australian universities (Wanner \& Palmer, 2015). To prepare for future workplace roles, it is important that students are provided with opportunities to develop confidence in their work and be able to measure their competence against appropriate standards (Boud, 2015). To develop such skills, students need opportunities to both judge the quality of others work, and to compare their work with others work. One such mechanism for providing these opportunities is peer-review activities.

Giving students opportunities to receive and provide feedback to peers can improve student learning without increasing lecturer workload, moving students from passive to active learners (Wanner \& Palmer, 2018), whilst increasing social connectedness (Crowe, Silva, \& Ceresola, 2015), and social networking opportunities for some (Harland et al., 2017). Peer review not only leads to an improvement in students' ability to judge and improve their own work (Boud, 2015; Harland et al., 2017) but also develops employability skills such as critical thinking; collaboration; sensitive and constructive communication, while supporting independent, self-regulated learning (Moore \& Teather, 2013). Students who engaged in peer-review processes demonstrated increased ability to provide constructive feedback; avoided common writing errors; experienced exposure to different ideas and perspectives (Gaynor, 2019); were more engaged with their work (Dowse, Melvold, \& McGrath, 2018); and were provided with opportunities to reflect on the shortcomings of their work and subsequently improve it (Mulder, Pearce \& Baik, 2014). Peer-review processes increased student awareness that feedback is available from others as well as the lecturer (Crowe et al., 2015; Harland et al., 2017), helping them to understand their work in relation to the standards required from the lecturer's perspective (Nicol et al., 2014). Yalch (2019) reports students who offered robust critique received higher grades for their own work.

Although there are many benefits for students who engage in peer-review opportunities, there are challenges. Students may perceive the time spent on peer-review as additional work that displaces other learning or teaching activities (Crowe et al., 2015). Students reported they found it difficult to: identify areas for improvement in the work of others; to write feedback (Moore \& Teather, 2013); and were uncomfortable critiquing their peers' work (Harland et 
al., 2017). Some felt the effort made to provide feedback was not matched by the feedback they received on their own work (Mulder et al., 2014). Students have also reported a lack of confidence in providing feedback, and those accustomed to traditional lecturer-led learning environments may struggle with the transition to learner-centred activities (Varaprasad, 2016). To simplify the peer-review process and ensure students enjoy a positive and beneficial peerreview experience, it is necessary to provide students with guidelines and criteria (Mulder, Pearce, \& Baik, 2014), good support and structured processes (Harland et al., 2017), and opportunities to practice (Scherf, 2017).

The lead author is the Lecturer and Unit Coordinator for HST3100 Child \& Adolescent Health, a third-year health promotion unit taught in the School of Medical and Health Sciences at Edith Cowan University (ECU) in Western Australia. Student feedback from the previous semester indicated a lack of clarity about assessment requirements and that the assignment feedback provided by the lecturer was not clear enough. A peer-review assessment was, therefore introduced the next time the unit was delivered. The original assessment tasks were changed to be 'scaffolded' in nature. That is, the original unrelated essay-style tasks were replaced with a 500-word rationale (addressing the subject of the peer-review process), which then formed the basis of the second assessment. The restructuring of the unit, including the scaffolded assessments in conjunction with peer review activities, required students from heterogeneous backgrounds to work together, exposing them to different ways of working and different writing styles (Wood, Bruner, \& Ross, 1976). Scaffolded learning occurs when students can work on a small part of their assignment (in this case, the 500-word rationale), receiving feedback from their peers and the lecturer to improve their work for future assignments (Newman, \& Holzman, 2013).

Peer-review processes were embedded in unit learning activities for Semester 1, 2019, and their acceptability and perceived benefit to students was assessed using pre- and post-surveys among on- and off-campus students enrolled in the unit. The overarching aim of this project was to improve student satisfaction with the unit, whilst evaluating students perceptions of the peer-review process and the student-reported outcomes associated with engaging in these learning activities.

\section{Methods}

\subsection{Overview}

The study design was based on a similar study conducted by Moore and Teather (2013). HST3100 students were asked to draft a 500-word rationale to support a proposed Health Promotion program on a health issue of their choice, relevant to child and adolescent health. Students were then asked to share their rationale with another student and provided with instructions on how to follow a structured peer-review process. Table 1 presents a structured 
plan outlining the process implemented in the first six weeks of semester.

\section{Table 1. Peer-review process}

\section{Step 1: Weeks $1 \& 2$ Prior to the practice and actual review sessions}

Students advised of the changes to the assignment tasks (as a result of student feedback) and advised they would be asked to complete a survey before and after engaging in the peer-review process.

Students asked to introduce themselves to others in class, or via the discussion boards for online students, to negotiate with potential peers to review their draft assignment (Week 4).

Step 2: Week $3 \quad \begin{aligned} & \text { Prior to the actual review session } \\ & \text { Students provided with the opportunity to practice peer-reviewing. This } \\ & \text { process involved: }\end{aligned}$
B $\quad \begin{aligned} & \text { Being provided with a sample assignment from the previous } \\ & \text { year and the assessment criteria to review the sample. }\end{aligned}$
- $\begin{aligned} & \text { Lecturer provided coaching on how to provide constructive } \\ & \text { feedback. }\end{aligned}$
- Students reviewed the sample assignments individually and
wrote feedback on the feedback template provided.
$\begin{aligned} & \text { Students formed small groups to discuss and compare the } \\ & \text { individual feedback they had provided, and to reach consensus } \\ & \text { about the most appropriate feedback to provide (via discussion } \\ & \text { boards for online students). }\end{aligned}$
Students completed a Pre-Peer Review Survey.

Step 3: Week 4 The actual review session

Students brought copies of their draft assignment to class. Online students shared these via the unit discussion boards or student email.

Students reviewed the draft assignment of one other student.

Students were asked to provide considered, professional and respectful comments to their peers on the template provided.

Students attached the completed template to the draft assignment, returned it to their peer and further verbal dialogue and clarification was encouraged.

\section{Step 4: Week 5 Post peer-review}

Students were asked to consider the feedback they received from their peerreviewer and advised to revise their assignments considering this feedback before submitting a final version for assessment.

\section{Step 5: Week $6 \quad$ Follow-up}

Students completed a Post-Peer Review Survey to assess the perceived value of the process. 


\subsection{Recruitment}

All HST3100 students, both on- and off-campus, were eligible to participate in the evaluation of the peer-review process. Recruitment took place during class in Week 1, when the lecturer outlined the project and explained the extent of student participation. A live tutorial (recorded for students unable to attend) was hosted for off-campus students to explain the peer-review process and invite participation. On-campus students were provided with a written information letter to retain, and consent was embedded in the online survey. On-campus students who did not have access to an electronic device, were provided with a paper-based consent document, which was signed and returned to the lecturer. Off-campus students were provided with a written information letter issued via student email, and consent was embedded in the electronic survey.

\subsection{Data Collection}

Both surveys were based on the work of Moore and Teather (2013) and were assessed for face and content validity by the second author, an expert in research design, higher education assessment design and child and adolescent health. The surveys were administered electronically to all students via Qualtrics, and paper copies provided for on-campus students without access to an electronic device in class. Both surveys included closed and open-ended questions, but neither survey collected any identifying data, ensuring participant anonymity. In Week 3, the Pre- Peer Review Survey assessed students' prior experiences of peer-review; their experiences of the practice peer-review exercise; and their feelings about the actual peerreview process to be conducted the following week. The Post-Peer Review Survey was administered in Week 6, following submission of the revised assignment, and measured students' perceptions on the usefulness of the peer-review exercise on their own work and their feelings about engaging in similar activities in the future.

\subsection{Data Analysis}

Data from paper-based surveys were manually entered into Qualtrics and merged with the electronically collected data. The datasets were downloaded to SPSS and simple descriptive analytics assessed students' experiences before and after the peer-review exercise. Openended question responses were also collated in Qualtrics, and simple, descriptive analysis was conducted.

\subsection{Ethics}

Ethics clearance was obtained from the Human Research Ethics Committee at ECU (\# 201900024). The peer-review exercise was an integral part of the first assignment and students were required to complete this. The completion of the Pre-and/or Post Peer Review Surveys was, however, voluntary. The data were stored securely on a university server, were password protected, and access restricted to members of the research team. 


\section{Results}

\subsection{Demographic Profile}

The majority of students who completed the two surveys were enrolled in the Bachelor of Health Science degree on-campus (Table 2). Participation rates were higher for on-campus students pre-peer review (85\%) compared to off-campus (25\%), and post-peer review (53\% vs $20 \%$ respectively).

Table 2. Student demographic profile Pre- and Post-Peer Review Surveys

\begin{tabular}{llcc}
\hline & & $\begin{array}{c}\text { Pre- peer review } \\
\text { task }(\mathbf{n}=\mathbf{3 2})\end{array}$ & $\begin{array}{c}\text { Post- peer review } \\
\text { task }(\mathbf{n}=\mathbf{2 1})\end{array}$ \\
\hline $\begin{array}{l}\text { What course of } \\
\text { study are you } \\
\text { currently enrolled in } \\
\text { at ECU? }\end{array}$ & $\begin{array}{l}\text { Bachelor of Health } \\
\text { Science }\end{array}$ & $62.50 \%(\mathrm{n}=20)$ & $52.38 \%(\mathrm{n}=11)$ \\
& $\begin{array}{l}\text { Bachelor of Education } \\
\text { (Secondary) }\end{array}$ & $21.88 \%(\mathrm{n}=7)$ & $23.81 \%(\mathrm{n}=5)$ \\
& Other & $15.63 \%(\mathrm{n}=5)$ & $23.81 \%(\mathrm{n}=5)$ \\
Mode of study & On-campus & $84.38 \%(\mathrm{n}=27)$ & $80.95 \%(\mathrm{n}=17)$ \\
& Off-campus & $15.63 \%(\mathrm{n}=5)$ & $19.05 \%(\mathrm{n}=4)$ \\
\hline
\end{tabular}

\subsection{Pre- Peer Review Survey results}

Students were asked if they had previously reviewed another student's work, either formally (as part of a unit of study) or informally. The majority of students $(78.1 \%, \mathrm{n}=25)$ had previously engaged in peer-review activities and most of these respondents $(96 \%, \mathrm{n}=23)$ had been provided with formal guidance on how to conduct the peer-review by their lecturer. The main benefits of engaging in peer-review were identified as: helping students to reflect on the quality of their own work $(72 \%, \mathrm{n}=23)$; improving communication skills $(62 \%, \mathrm{n}=20)$; and learning how to collaborate with others $(59 \%, \mathrm{n}=19)$.

Some students identified concerns or anxieties about being asked to review the work of others, especially in terms of being able to provide constructive feedback. Other students viewed this as an opportunity to improve their own work by comparing it with the work of others and expressed confidence in their ability to provide 'polite and constructive feedback'. When asked to describe their feelings about another student providing feedback on their draft assignment, some students expressed positive sentiments. They felt their peers would critique their work with 'honesty' and the advantages provided through subsequent improvements would render the peer-review process beneficial. This peer-review experience was not viewed 
as positive by all, and some participants noted their written English skills may make this experience 'uncomfortable' or 'embarrassing'.

Most students $(97 \%, \mathrm{n}=31)$ felt 'well-prepared' or 'somewhat-prepared' to review another student's assignment following the practice exercise (Table 3).

Table 3. Preparedness for peer-review following practice exercise

\begin{tabular}{lc}
\hline Level of preparedness & $\boldsymbol{\%}(\mathbf{n})$ \\
\hline Well-prepared & $65.6(\mathrm{n}=21)$ \\
Somewhat prepared & $31.25(\mathrm{n}=10)$ \\
Unsure & $3.1(\mathrm{n}=1)$ \\
Slightly unprepared/ Completely unprepared & $0.00(\mathrm{n}=0)$ \\
\hline
\end{tabular}

\subsection{Post-Peer Review Survey results}

Almost $90 \%$ of respondents reported enjoying the peer-review process. Three-quarters of respondents $(76 \%, \mathrm{n}=16)$ noted that the peer-review process helped them with their own assignment, $90 \%(\mathrm{n}=19)$ modified their assignment as a result of the feedback they received, and $67 \%(n=14)$ modified their assignment as a result of the feedback they provided. The most useful parts of the peer-review activity were reported as receiving feedback $(43 \%, n=9)$ or both, i.e., giving and receiving feedback $(38 \%, \mathrm{n}=8)$. Most students rated the quality of the feedback they received as excellent $(71 \%, \mathrm{n}=15)$ or average $(24 \%, \mathrm{n}=5)$.

Students were asked about other benefits of completing the peer-review activity, apart from improving their own assignment (Table 4). Critical thinking and written communication skills were the main benefits reported. The majority of respondents $(81 \%, \mathrm{n}=17)$ reported they would choose to participate in future peer-review activities, and $86 \%(n=18)$ agreed the activity should be included the next time the unit is offered.

Table 4. Benefits of engaging in a peer-review process

\begin{tabular}{lc}
\hline Benefits of peer-review & $\boldsymbol{\%}(\mathbf{n})$ \\
\hline My critical thinking skills improved & $32.6(\mathrm{n}=16)$ \\
My written communication skills improved & $26.5(\mathrm{n}=13)$ \\
My listening skills improved & $18.4(\mathrm{n}=9)$ \\
My negotiation skills improved & $12.2(\mathrm{n}=6)$ \\
\hline
\end{tabular}


Students were asked to respond to open-ended questions about parts of the peer-review process they liked or disliked. Five main themes were identified in these responses. Negative responses included the view that 'feedback [they received] wasn't helpful', since the reviewer might not fully understand the health topic being presented, while another student commented that the process added extra time to the completion of the assignment.

Positive feedback was far more common however, with students commenting that 'feedback = bettermarks'; and that the process allowed them the opportunity to clarify and further focus their work. Learning from reviewing the work of another student included improvement of specific writing skills (how to use joining words); how to provide constructive feedback, and improved understanding of the standard expected in the assignment through comparison of one's own work with that being reviewed. This participant quote captures the positive aspects of the experience:

I really enjoyed getting to see all of the different ways to write a paper, and how different everyone's train of thought works. I also enjoyed learning a bit about my peer review partner's topic.

Use of the marking rubric, attention to sentence structure and readability were the key learnings from other students reviewing their work. Students made changes after their work had been reviewed, including editing, adding more information and closer attention to sentence and paragraph structure. This sentiment is illustrated in the following quote:

By peer reviewing another student's paper, I could see things that I liked structurally about their paper that I wanted to incorporate into my writing.

An online student summarised the usefulness of the activity from her perspective:

" [I] liked hearing another point of view - being an online student it's nice to communicate with another student and help each other understand the topic/assignment better".

The negative and positive aspects of reviewing another student's work are summarised below (Table 5): 
Table 5. Students reported feelings about peer-reviewing another student's work.

\begin{tabular}{|c|c|}
\hline Negative & Positive \\
\hline - $\quad$ Hesitant & - Just focused on rationale \\
\hline - Apprehensive & - Enjoyable \\
\hline - $\quad$ Nervous & - Great \\
\hline - Awkward & - Opportunity to rethink own work \\
\hline \multirow[t]{5}{*}{ - $\quad$ Fearful of offending } & - Happy \\
\hline & - Enable me to think critically \\
\hline & - $\quad$ Beneficial \\
\hline & - Comfortable \\
\hline & - Not an issue \\
\hline
\end{tabular}

\subsection{Student satisfaction (UTEI) results}

University Teaching and Evaluation (UTEI) student feedback data for 2018/19 was downloaded from the University's database. Overall mean satisfaction with the unit increased threefold among on-campus students after the introduction of the peer-review assessment (Table 6). Overall mean satisfaction increased by $61 \%$ among off-campus students (61 vs. 0 , Table 6). Overall university averages for 'satisfied with the unit' are typically around 50 and mean scores of around 30 or less (approx. 65\% agreement) suggests room for improvement, compared to scores above 65 (approx. 90\% agree) which suggest a unit in good health from a student point of view (ECU, n.d.)

Table 6. Overall student satisfaction of unit from UTEI data 2018 vs 2019

\begin{tabular}{lcccccc}
\hline Overall Satisfaction & \multicolumn{2}{c}{ Mean } & \multicolumn{2}{c}{ \% Agreement } & \multicolumn{2}{c}{ N } \\
& \multicolumn{2}{l}{} & & & & \\
\hline Year & 2018 & 2019 & 2018 & 2019 & 2018 & 2019 \\
On-campus & 17 & 58 & 62 & 85 & 21 & 13 \\
Off-campus & 0 & 61 & 36 & 100 & 11 & 9 \\
\hline
\end{tabular}




\section{Discussion}

Effective feedback is essential to support student success and develop employability skills. This study aimed to improve student satisfaction with a unit of study, whilst assessing student perceptions of the peer-review process. The reported outcomes resulting from students engaging with these learning activities were mainly positive.

There was a significant increase in overall student satisfaction with the unit, especially among off-campus students (Table 6). This may in part be attributable to the peer-review activity, but also because the unit had been restructured, and two interrelated assignments introduced to support scaffolded learning (Newman \& Holzman, 2013). Given the low participation rates for survey completion among off-campus students (25\% pre- and $20 \%$ post-survey) it is important to encourage these students to provide feedback to inform cycles of continuous improvement in teaching and learning. Despite the low response rate, the positive results are never-the-less encouraging.

The Pre- Peer- Review Survey revealed that most respondents found the practice exercise useful in preparing them for the actual peer-review exercise. Many had previously engaged in peer-review activities and recognised how this provided opportunities to increase important employability skills such as self-reflection, communication and collaboration, findings such as those reported by Moore and Teather (2013). However, some students, for whom English was not their first language, expressed concerns that they would feel 'embarrassed' or 'uncomfortable' about providing peer-review feedback to their fellow students. To address this issue, future peer-review exercises could include assigning students to heterogeneous groups of three to five students (rather than the one-to-one process adopted for this study). This would expose students to different writing styles and levels of competence, whilst strengthening social connections, social skills and thus increasing confidence to provide feedback (Crowe et al., 2015).

The Post-Peer Review Survey revealed 90\% of respondents found the experience useful and reported it helped them with their own assignment, similar to other research (Varaprasad, 2016). Respondents reported receiving feedback was more beneficial than giving feedback, whereas Moore and Teather (2013) reported students valued both giving and receiving feedback. This finding also contrasted that of Cassidy and Bailey (2018) who reported higherlevel improvements associated with giving peer-review feedback than receiving it. This may be explained by the quality of the feedback received - in this study, two students commented that the quality of the 'feedback [they received] wasn't helpful'. Similarly, Mulder et al. (2014) reported student concerns about the level of effort spent providing feedback not being reciprocated, and this could perhaps be mitigated in future peer-review activities by assigning students to larger, heterogeneous groups, or by assigning marks to the peer-review feedback (Moore \& Teather, 2013). 
Students who completed the surveys reported their critical thinking and communication skills had improved as a result of the peer-review exercise (Table 4) and the overwhelming response to the peer-review activity was positive (Table 5). The peer-review process was described as 'beneficial', providing students opportunities to rethink their own work and enabling critical thinking. This suggests students were demonstrating important professional skills, reflecting the ability to make sound evaluative judgements and communicate them tactfully (Nicol et al., 2014).

The limitations of this study include the small non-random sample, thus these results are not generalizable to the wider student population. The off-campus student cohort was particularly small, so looking forward, more effective strategies to engage this group should be developed to gather their perceptions, as these are likely to differ from those of on-campus students. In conclusion, students reported the peer-review process as beneficial. The peer-review activity positioned feedback as an important learning tool for assessment tasks and helped students improve a range of skills required for their future careers. Overall student satisfaction with the unit increased dramatically, further supporting the worth of peer-review feedback as an important teaching and learning technique. Future research should focus on providing opportunities to engage with peer-review activities in larger, heterogeneous groups to increase student confidence and develop important employability skills. Ultimately, peerreview is a useful teaching and learning tool that can embed the concept of active learning, and nurture students to become desirableemployees.

\section{References}

Boud, D. (2015). Feedback: Ensuring that it leads to advanced learning. The Clinical Teacher, 12(1), p. 3-7. https://doi.org/10.1111/tct.12345

Crowe, J., Silva, T., \& Ceresola, R. (2015). The effect of peer review on student learning outcomes in a research methods course. Teaching Sociology, 43(3), 201-213. https://doi.org/10.1177/0092055X15578033

Dowse R., \& Melvold J., \& McGrath K. (2018). Students guiding students: Integrating student peer review into a large first year science subject. A Practice Report. Student Success, 9(3), 79-86. doi: 10.5204/ssj.v9i3.471

Edith Cowan University. Unit and Teaching Evaluation Instrument (UTEI). (n.d.). Available from: https://intranet.ecu.edu.au/staff/centres/strategic-and-governance-services/ourservices/strategy-and- performance/surveys-services/unit-and-teaching-evaluationinstrument-utei.

Gaynor, J. (2019). Peer review in the classroom: Student perceptions, peer feedback quality and the role of assessment. Assessment \& Evaluation in Higher Education, https://doi.org/10.1080/02602938.2019.1697424

Harland, T., Wald, N., \& Randhawa, H. (2017). Student peer review: Enhancing formative feedback with a rebuttal. Assessment and Evaluation in Higher Education, 42(5), 801811. https://doi.org/10.1080/02602938.2016.1194368 
Moore C., \& Teather S. (2013). Engaging students in peer review: Feedback as learning. In Special issue: Teaching and learning in higher education: Western Australia's TL Forum. Issues in Educational Research. 23(2), p. 196-211. http://www.iier.org.au/iier23/moore.html

Mulder R., Pearce J., \& Baik C. (2014). Peer review in higher education: Student perceptions before and after participation. Active Learning in Higher Education, 15(2), 157-171. https://doi.org/10.1177\%2F1469787414527391

Newman F., \& Holzman L. (2013). Lev Vygotsky: Revolutionary scientist. New York, New York: Psychology Press, Taylor \& Francis Group. https://doi.org/10.4324/9780203758076

Nicol D., Thomson A., \& Breslin C. (2014). Rethinking feedback practices in higher education: a peer review perspective. Assessment \& Evaluation in Higher Education. 39(1), 102-22. https://doi.org/10.1080/02602938.2013.795518

Scherff, L. (2017). The value of peer review in English language arts classrooms. Voices from the Middle, 25(2), 56-58.

Varaprasad C. (2016) In-class peer feedback: Effectiveness and student engagement. The Asian Journal of Applied Linguistics, 3(2), 155-172. Retrieved from https://pdfs.semanticscholar.org/af79/15403cc749060fb619d7b626ec7edfb2cf28.pdf?_g $\mathrm{a}=2.113445575 .1581543610 .1577778892-529616086.1577778892$

Wanner T., \& Palmer E. (2018). Formative self- and peer assessment for improved student learning: The crucial factors of design, teacher participation and feedback. Assessment \& Evaluation in Higher Education, 43(7), p. 1032-1047. https://doi.org/10.1080/02602938.2018.1427698

Wanner T., \& Palmer E. (2015). Personalising learning: Exploring student and teacher perceptions about flexible learning and assessment in a flipped university course. Computers \& Education, 88, 354-69. https://doi.org/10.1016/j.compedu.2015.07.008

Wood D., Bruner J., \& Ross G. (1976). The role of tutoring in problem solving. Journal of Child Psychology and Psychiatry, 17(2), 89-100. https://doi.org/10.1111/j.14697610.1976.tb00381.x

Yalch, M., Vitale, E., \& Ford, J. (2019). Benefits of peer review on students' writing. Psychology, Learning \& Teaching, 18(3), 317-325. DOI: 10.1177/1475725719835070 